\title{
Clonagem, expressão, caracterização molecular da proteína de superfície MSP5 da amostra PR1 de Anaplasma marginale e sua aplicaçáo em um teste de ELISA por competiçáo
}

\author{
Cloning, expression, molecular characterization of the MSP5 protein from PR1 strain of \\ Anaplasma marginale and its application in a competitive enzyme-linked immunosorbent test \\ Elizabete Regina M. Marana ${ }^{1}$; Flora S. Kano ${ }^{2}$; Josy C. Vicentini³; Rafael S. Spurio ${ }^{3}$; \\ Marcela Ribeiro ${ }^{3}$; Adriana Letícia M. Coelho ${ }^{3}$; Marilda C. Vidotto ${ }^{1}$; Odilon Vidotto ${ }^{1 *}$ \\ ${ }^{1}$ Departamento de Medicina Veterinária Preventiva, Centro de Ciências Agrárias, Universidade Estadual de Londrina - UEL \\ ${ }^{2}$ Programa de Pós-Graduaçáo em Ciência Animal, Universidade Estadual de Londrina - UEL e Bolsista CAPES \\ ${ }^{3}$ Curso de Medicina Veterinária, Universidade Estadual de Londrina - UEL e Iniciação Científica CNPq
}

Recebido em 2 de Agosto de 2007

Aprovado em 13 de Março de 2009

\section{Resumo}

No presente trabalho, um teste imunoenzimático por competição (cELISA) foi padronizado com a proteína recombinante de superfície rMSP5, clonada a partir do gene $m s p 5$ do isolado PR1 de $A$. marginale. $\mathrm{O}$ sequenciamento mostrou que o gene que codifica a rMSP5/PR1 tem 98\% de identidade com os isolados Flórida e Santa Maria, 97\% com isolados de Pernambuco, Brasil e Havana, Cuba e 91\% com A. centrale. O teste de cELISA-PR1 foi comparado com os testes de IFI e cELISA-USA. Para a padronização e validaçáo do cELISA-PR1, foram utilizados 380 soros bovinos comprovadamente positivos ou negativos pelo cELISA-USA. Desse total, 245 soros positivos eram de animais de área endêmica e 135 soros eram negativos, de área livre de anaplasmose. Na padronização, foram utilizados 283 soros de bovinos, dos quais 135 eram negativos e 148 positivos. Os testes de cELISA-PR1 e IFI apresentaram especificidade de 100 e 99,3\%, sensibilidade de 100 e $98 \%$, com coeficiente kappa de 0,993 e 0,978, respectivamente. Na validação do teste, foram utilizados 245 soros de bovinos de áreas endêmicas para anaplasmose, testados pelo cELISA-PR1 e IFI e apresentaram especificidade de 96,7 e 69,1\%, sensibilidade de 98,9 e 96,3\% e coeficiente kappa de 0,956 e 0,699, respectivamente. Esses resultados permitem afirmar que o teste de cELISA-PR1 apresentou performance equivalente ao cELISA-USA, podendo também ser utilizado em estudos epidemiológicos, programas de controle e movimentação internacional de animais, enquanto a IFI, com os resultados menos precisos apresentados, não deve ser utilizada em situaçóes que requerem maior rigor no diagnóstico.

Palavras-chave: Anaplasma marginale, ELISA, IFI, proteínas, bovinos.

\begin{abstract}
A competitive enzyme-linked immunosorbent test using the PR1 recombinant major surface protein 5 (rMSP5-PR1-ELISA) of Anaplasma marginale was standardized and validated using sera from anaplasmosis free and endemic regions. The sequencing of the $m s p 5$ gene of PR1 isolate showed $98 \%$ of identity with the Florida and Saint Maries isolates, $97 \%$ with Brazil (Pernambuco) and Havana isolates; and 91\% with $A$. centrale. The cELISA-PR1 test was compared to IFI and cELISA-USA. For the standardization and validation of the cELISA-PR1, 380 bovine sera were used, whereas 245 truly positives and 135 truly negatives sera tested by the cELISA-USA. In the standardization of the cELISA-PR1 135 negative and 148 positive bovine sera were used. The cELISA-PR1 and IFI tests showed 100 and $99.3 \%$ specificity, 100 and 98\%, sensibility, and a kappa coefficient of 0.993 and 0.978 , respectively. For test validation, 245 bovine sera from an anaplasmosis endemic area were analyzed by the cELISA-PR1 and IFI, which showed 96.7 and $69.1 \%$ specificity, 98.9 e $96.3 \%$ sensibility and kappa coefficient of 0.956 and 0.699 , respectively. These results indicate that the cELISA-PR1, likewise the cELISA-USA, could sensitively and specifically detect cattle naturally infected with $A$. marginale and would be recommended for epidemiological studies, eradications program, and regulation of international cattle movement, while IFI, which presented lower specificity should not be used in situations that demand more specific diagnosis.
\end{abstract}

Keywords: Anaplasma marginale, ELISA, IFI, protein, cattle.

\footnotetext{
*Autor para correspondência: Odilon Vidotto

Departamento de Medicina Veterinária Preventiva, Centro de Ciências Agrárias,

Universidade Estadual de Londrina - UEL, Campus Universitário, Rod. Celso

Garcia Cid, PR 445, km 380, CP 6001, CEP 86051-990 Londrina, PR, Brasil;

Apoio: Fundação Araucária do Paraná e CNPq; e-mail: vidotto@uel.br;
} 


\section{Introdução}

Anaplasma marginale é um patógeno hemotrópico da ordem Rickettsialles, família Anaplasmataceae (DUMLER et al., 2001), agente etiológico da anaplasmose bovina (KREIER; RISTIC, 1981). O carrapato Boophilus microplus é o vetor mais importante de A. marginale no Brasil e em outras regióes tropicais e subtropicais. A doença causa perda de peso, abortamento, redução da produção leiteira e mortalidade. Animais que se recuperam da doença, usualmente permanecem infectados, servindo como reservatório a outros animais susceptíveis (KESSLER, 2001).

Anaplasma marginale possui em sua membrana externa seis proteínas principais de superfície (MSPs): MSP1a, MSP1b, MSP2, MSP3, MSP4, MSP5 (PALMER; McGUIRE, 1984; OBERLE et al. 1993; VISSER et al., 1992; ALLEMAN et al., 1997; BARBET et al., 2001). A MSP5 tem se mostrado conservada em todos os isolados de $A$. marginale, $A$. centrale e $A$. ovis, com reaçôes cruzadas entre essas espécies. A MSP5 apresenta epítopos de superfície imunodominantes que são reconhecidos pelo anticorpo monoclonal ANAF16C1, específico para MSP5, o que possibilita sua utilização como antígeno em testes imunoenzimáticos por competição (cELISA) para o diagnóstico de anaplasmose bovina e avaliação dessas proteínas em rebanhos de várias regiôes geográficas (NDUNG'U et al., 1995; KNOWLES et al., 1996; REYNA-BELLO et al., 1998).

Diversos testes sorológicos foram avaliados para a pesquisa de anticorpos contra $A$. marginale em estudos epidemiológicos. Entre eles, a Fixação de Complemento (RODGERS et al., 1994), Aglutinação pelo Látex (PEREZ et al., 1994), Conglutinação (ROSE et al., 1978), Imunofluorescência Indireta (JONGEJAN et al., 1988; FRAGADA et al., 1991), Ensaios Imunoenzimáticos (ELISA) (NAKAMURA et al., 1988; NIELSEN et al., 1996) e ELISA por competição (cELISA) (KNOWLES et al., 1996; TORIONI et al., 1998).

No Brasil, os estudos sobre a prevalência da anaplasmose bovina têm detectado a presença do $A$. marginale em diferentes regióes do país. Em levantamento utilizando a técnica do esfregaço sanguíneo corado pelo Giemsa, Oliveira et al. (1992) encontraram, em Sergipe, $12,3 \%$ de animais positivos. O Teste de Conglutinação Rápida (TCR) detectou 97,6\% de animais sororreagentes na Bahia (ARAÚJO et al., 1995). Madruga et al. (2000) encontraram, respectivamente, pela IFI e ELISA, 97,2 e 96,9\% de animais soropositivos em região considerada de estabilidade enzoótica do estado da Bahia.

O cELISA utiliza como antígeno a proteína recombinante de $19 \mathrm{kDa}$ do $A$. marginale (MSP5) e o anticorpo monoclonal ANAF16C1 como conjugado (KNOWLES et al., 1996). Isolados de $A$. marginale de diferentes regióes do Brasil foram analisados por Western Blotting, e a MSP5 se mostrou conservada em todas as amostras (KANO et al., 2002; OLIVEIRA et al., 2003).

O teste de cELISA foi utilizado em levantamentos sorológicos de anaplasmose em rebanhos no estado do Paraná. Na região de Londrina, Vidotto et al. (1998) encontraram 87,56\% de animais positivos em rebanhos mistos; Andrade et al. (2001), 92,94\% em rebanhos leiteiros; Yoshihara et al. (2003) encontraram 76,10\% de bovinos reagentes em rebanhos de gado de corte da região de Umuarama, região Noroeste do estado.
Os objetivos deste trabalho foram a clonagem do gene da MSP5, expressão e caracterização molecular da proteína recombinante MSP5 de $A$. marginale e sua utilização em um teste imunoenzimático por competição (cELISA), a partir do isolado PR1 da região de Londrina, Paraná.

\section{Material e Métodos}

\section{Obtenção do DNA de A. marginale e amplificação do gene MSP5}

A extraçáo de DNA foi realizada a partir de sangue parasitado obtido de bezerro infectado pelo isolado PR1 (KANO et al., 2002) de $A$. marginale, utilizando-se o kit Puregene Genta System ${ }^{\odot}$, segundo recomendaçóes do fabricante.

O gene que codifica a MSP5 foi amplificado com oligonucleotídeos iniciadores (primers) sense 5'GAATTCATGA GAATTTTCAAGATTGTG3'(posiçóes 121 a 138) e anti-sense 5’AGAATTAAGCATGTGACCGCTG 3' (posiçóes 725-747), confeccionados a partir da sequência do gene msp5 (GenBank M93392). A amplificação de $100 \eta \mathrm{g}$ de DNA do isolado PR1 de A. marginale foi realizada com Taq DNA polimerase $\left(\right.$ Invitrogen $\left.^{\mathrm{TM}}\right)$, utilizando-se 30 ciclos $\left(94^{\circ} \mathrm{C}\right.$ por 1 minuto; $58^{\circ} \mathrm{C}$ por 1 minuto; $72{ }^{\circ} \mathrm{C}$ por 1 minuto) no volume de $50 \mu \mathrm{L}$ em termociclador (Perkin Elmer DNA Thermal Cycler 9600, Norwalk, CT). O produto amplificado foi visualizado em gel de agarose $2 \%$, corado com brometo de etídeo, utilizando-se padrôes de peso molecular de 100 pb (100 pb DNA ladder-Life Technologies, MD, EUA).

\section{Clonagem e sequenciamento do gene msp5 no vetor pCR4-TOPO TA}

O produto da PCR do gene msp5 foi clonado no vetor de sequenciamento pCR4-TOPO TA (Invitrogen ${ }^{\circledR}$ ) e sequenciado usando BigDye Terminator (Applied Biosystems, CA, EUA) e os primers: sense e anti-sense do bacteriófago M13 e os primers 1 e 2 (VISSER et al., 1992). As sequências foram submetidas ao programa de análise Phred/Phrap/Consed (ALTSCHUL et al., 1990) e, em seguida, foram submetidas aos programas BLASTn e BLASTx, respectivamente (ALTSCHUL et al., 1990, 1997), para confirmar a identidade da sequência.

\section{Clonagem do gene msp5 no vetor pRSET e expressão da MSP5 recombinante}

Os primers sense (5'GAATTCATGAGAATTTTCAAGATT GTG3'), contendo, no início, um sítio de restrição para a enzima BamH I, e anti-sense (5'AGAATTAAGCATGTGACCGCTG3'), sem o código de parada, foram confeccionados a partir da sequência do gene $m s p 5$ sequenciado do isolado PR1. A PCR de $100 \eta \mathrm{g}$ do DNA do isolado PR1 de $A$. marginale foi realizada com a enzima Pfx DNA polimerase Platinum ${ }^{\oplus}$ (Invitrogen ${ }^{\circledR}$ ), utilizando-se 30 ciclos (94 ${ }^{\circ} \mathrm{C}$ por 1 minuto; $55^{\circ} \mathrm{C}$ por 1 minuto; $68^{\circ} \mathrm{C}$ por 1 minuto) no volume de $50 \mu \mathrm{L}$, conforme especificaçóes do fabricante. 
O gene msp 5 amplificado foi clivado com a enzima de restriçấo BamHI e purificado pela extração do DNA em gel de agarose $1 \%$ com kit Concert ${ }^{\mathrm{TM}}$ Rapid Gel Extration System (GIBCOBRL $\left.{ }^{\oplus}\right)$, conforme instruçôes do fabricante. $\mathrm{O}$ vetor $\operatorname{pRSET}_{\mathrm{B}}$ (Invitrogen ${ }^{\circ}$ ) foi clivado com BamHI e Pvu II e utilizado na ligação com o fragmento $m s p 5 / \mathrm{BamHI}$ com T4 DNA ligase (Invitrogen $^{\circ}$ ). A transformação foi realizada em E. coli One Shot ${ }^{\text {TM }}$ TOP 10 competente (Invitrogen ${ }^{\circ}$ ), segundo as instruçóes do fabricante. Os plasmídios recombinantes das colônias transformantes foram extraídos segundo Sambrook et al. (1989).

A clonagem foi confirmada pela técnica de PCR do plasmídio recombinante ( $\mathrm{pRSET} / m s p 5$ ), utilizando-se os primers do gene $m s p 5$ e do vetor $\mathrm{pRSET}_{\mathrm{B}}$, e também pela utilização de clivagem com a enzima de restriçấo BamHI e sequenciamento. O plasmídio recombinante pRSET/msp 5 foi utilizado na transformação da bactéria E. coli BL21 Star (DE3) One Shot ${ }^{\mathrm{TM}}$ (Invitrogen ${ }^{\circledR}$ ) competente para a expressão da proteína MSP5 recombinante (rMSP5-PR1). As bactérias cresceram em Luria Bertani (LB), contendo $100 \mu \mathrm{g} \cdot \mathrm{mL}^{-1}$ de ampicilina a $37^{\circ} \mathrm{C}$ até $\mathrm{DO}_{500} 0,8 \mathrm{e}$ isopropyl- $\beta$-D-thiogalactoside (IPTG) (Invitrogen Life Technologies) adicionado na concentração de $1 \mathrm{mM}$ para indução da proteína. Alíquotas da cultura foram removidas após cada hora de indução para a escolha do melhor tempo de expressão. As bactérias foram coletadas por centrifugação e as proteínas analisadas das fraçóes solúvel e insolúvel em Gel SDS-PAGE a 12\%, segundo Laemmili (1970). Como padráo de massa molecular, foi utilizado o marcador de proteína pré-corado Bench Mark (Invitrogen ${ }^{\mathrm{TM}}$ ).

\section{Purificação da rMSP5-PR1}

A rMSP5-PR1 foi fusionada na cauda de poli-histidina (6xHis tag), facilitando sua purificação em coluna contendo níquel $\left(\mathrm{Ni}^{2+}\right)$ ligado à resina. Foi centrifugada na cultura de E. coli BL21/pRSET/msp5, obtida em litros de LB contendo $100 \mu \mathrm{g} . \mathrm{mL}^{-1}$ de ampicilina e IPTG $1 \mathrm{mM}$. As bactérias foram ressuspensas em tampão de lise $\left(100 \mathrm{mM} \mathrm{NaH} \mathrm{PO}_{4}, 10 \mathrm{mM}\right.$ Tris- $\mathrm{HCl}, 6 \mathrm{M}$ $\mathrm{Gu}-\mathrm{HCl}, \mathrm{pH}$ 8.0) e adicionado inibidores de proteases PMSF (phenylmethylnilfonyl fluoride) $1 \mathrm{mM} \mathrm{e} \mathrm{TCLK} \mathrm{(n \alpha -p} \mathrm{Tosyl} \mathrm{L-lysine}$ chloromethyl Ketone) 0,1 mM. Após incubação por 1 hora em temperatura ambiente, a solução foi centrifugada a $10.000 \times \mathrm{g}$ por 30 minutos em temperatura ambiente, e o sobrenadante foi recolhido e conservado a $-20^{\circ} \mathrm{C}$. O sobrenadante foi adicionado à coluna contendo resina NI-NTA Agarose (QIAGEN MOD 30210) e homogeneizado gentilmente por 1 hora em temperatura ambiente. A rMSP5-PR1 foi purificada sob condiçóes híbridas de acordo com o protocolo do fabricante $\left(\mathrm{QIAGEN}^{\mathrm{T} M}\right)$. A concentração da proteína foi determinada em espectrofotômetro Cintra 5 em comprimento de onda de $595 \mathrm{~nm}$ pelo método de Bradford (1976).

\section{Caracterização antigênica da rMSP5-PR1 pela técnica de Western-blotting}

A rMSP5-PR1, as proteínas totais do isolado de $A$. marginale PR1 e rMSP5-MBP do isolado Flórida (TORIONI DE ECHAIDE et al., 1998) foram separadas em gel de poliacrilamida $12 \%$ e, em seguida, transferidas para a membrana de nitrocelulose (Probind
45 membrane roll - Pharmacia Biotech ${ }^{\odot}$ ) com $30 \mathrm{~V}$ (TOWBIN; GORDON et al., 1984) por 18 horas. A membrana foi bloqueada com PBS contendo $0.1 \%(\mathrm{v} / \mathrm{v})$ de Tween 20 e $5 \%$ de leite em pó desnatado, sob agitação por 1 hora, em temperatura ambiente. Após as lavagens, as membranas foram incubadas com o anticorpo monoclonal AnaF16C1-HRPO (1:12.000), por 1 hora, sob agitação. A membrana foi revelada pelo método de quimioluminescência (ECL - Amershan Life ${ }^{\circ}$ ). Um marcador de massa molecular para proteína (Rainbow colored, Invitrogen Life Technologies) foi utilizado como padrão.

A antigenicidade de rMSP5-PR1 foi testada, utilizando-se soros de bovinos selecionados pelo cELISA, sendo dois soros negativos $\left(\mathrm{DO}_{490} 0,818\right.$ e 0,799 , respectivamente), dois soros positivos de animais naturalmente infectados pelo $A$. marginale $\left(\mathrm{DO}_{490} 0,089\right.$ e 0,080 , respectivamente), um soro de bovino inoculado com o isolado PR1 de $A$. marginale $\left(\mathrm{DO}_{490} 0,079\right)$, e soro de coelho anti-rMSP5-PR1 imunizado com rMSP5-PR1 diluído 1:5.000, incubados sob agitaçáo por 1 hora. Foram utilizados os conjugados anti-bovino IgG-Peroxidase (SIGMA A 5295), diluído 1:20.000, e anti-rabbit IgG-Peroxidase (SIGMA A 6145), diluído 1:5.000 e, após as lavagens, as membranas foram reveladas por quimioluminescência (ECL - Amershan Life ${ }^{\circ}$ ).

\section{Amostras de soro}

Para a padronização e validação do cELISA-PR1, foram utilizados 380 soros de bovinos comprovadamente positivos ou negativos pelo cELISA-USA. Desse total, 245 soros positivos eram oriundos de animais de área endêmica (128 do Rio Grande do Sul e 117 do Paraná) e 135 soros eram negativos, de Santa Vitória do Palmar, RS, área livre de anaplasmose. Para a padronização do cELISA-PR1 foram utilizadas 283 amostras de soros, das quais 135 negativas e 148 positivas, com $\mathrm{DO}_{490}$ superior ou inferior a 0,490, respectivamente.

\section{Teste de Imunofluorescência Indireta}

O teste de Imunofluorescência Indireta (IFI) foi utilizado para detecção de anticorpos anti- $A$. marginale, conforme o descrito por Goff et al. (1985), modificado por Madruga et al. (1986). $\mathrm{O}$ antígeno utilizado na confecção das lâminas foi produzido a partir da amostra PR-1 de $A$. marginale de acordo com o protocolo de passagens em bezerros esplenectomizados, desenvolvido por Madruga et al. (1986). Os soros com título $\geq 320$ foram considerados positivos.

\section{Teste de ELISA-USA de competição}

As amostras de soro foram testadas pela técnica de ELISA por competição (cELISA-USA), descrita por Knowles et al. (1996). O teste utilizou proteína recombinante rMSP5 ligada à maltose (rMSP5-MBP) como antígeno, e o anticorpo monoclonal ANAF16C1-HRPO ligado à enzima peroxidase. Os soros utilizados como controles negativos foram obtidos de animais negativos para A. marginale pelos testes de cELISA-USA e IFI. A porcentagem de inibição, representando um resultado positivo no cELISA, foi 
determinada a partir da densidade óptica (DO) a $490 \mathrm{~nm}$ em Leitor de ELISA Bio-Tek Instruments ${ }^{\circ}$, INC Modelo ELx 800). Os resultados foram expressos como porcentagem de inibição baseados na Equação (1) (TORIONI DE ECHAIDE et al., 1998):

$100-\frac{\left[\left(\mathrm{DO}_{490} \text { média do soro teste } \times 100\right)\right]}{\text { média da } \mathrm{DO}_{490} \text { do controle negativo }}$

\section{Avaliação do ELISA de competição utilizando a rMSP5-PR1}

A padronização do cELISA-PR1 foi realizada conforme descrito por Knowles et al. (1996) e Torioni de Echaide et al. (1998) com modificaçóes. As placas foram adsorvidas com 0,2 $\mu \mathrm{g}$ de rMSP5-PR1 por cavidade, diluída em tampão de adsorção carbonato/bicarbonato $\mathrm{pH}$ 9,6. O bloqueio foi realizado com Tampáo de Bloqueio $\mathrm{pH} 7,2$, adicionado de leite em pó desnatado a 2,5\%, diluído 1:2 em água destilada. Os soros controle positivo e negativo e os soros-teste foram previamente adsorvidos sob agitaçáo com lisado de $E$. coli BL21 Star (DE3) One Shot ${ }^{\mathrm{Tm}}$ (Invitrogen ${ }^{\circ}$ ), na concentração de $0,22 \mu \mathrm{g} \cdot \mathrm{mL}^{-1}$, diluídos em volumes iguais $(120 \mu \mathrm{L})$ no Tampão de Conjugado, adicionado de $1 \%$ de leite em pó desnatado e incubados por 30 minutos, para neutralizar anticorpos contra proteínas presentes em $E$. coli da microbiota intestinal de bovinos.

Após adição e incubação dos soros, as placas foram lavadas e adicionados $100 \mu \mathrm{L} /$ cavidade de conjugado monoclonal produzido em camundongo (anti-MSP5 ANAF16C1-HRPO), na diluição de 1:12.000, em Tampão de Bloqueio $\mathrm{pH}$ 7,2 2× diluído 1:2 em PPBS e incubado por 15 minutos em temperatura ambiente sob agitação. Após revelação com OPD e interrupção da reação com ácido sulfúrico, a determinação da porcentagem de inibição, representando um resultado positivo no cELISA, foi estabelecida a partir da densidade óptica (DO) a $490 \mathrm{~nm}$, em Leitor de ELISA (Bio-Tek Instruments ${ }^{\bullet}$ INC Modelo ELx 800) de 135 soros negativos da região livre de anaplasmose com DO média de $0,890 \pm 0,081$. O ponto de corte foi estabelecido a partir do valor de 3 desvio padrão (DP) abaixo da DO $(0,647)$, representando $27 \%$ de inibição. Nenhum dos soros negativos inibiu a ligação com anticorpo monoclonal em valores $\geq 27 \%$.

\section{Análise estatística}

Os testes cELISA-PR1 e IFI foram avaliados, utilizando-se como o cELISA-USA (KNOWLES et al., 1996). A sensibilidade, especificidade, valor preditivo (positivo e negativo) e concordância kappa foram calculados, utilizando-se o programa Epi Info 6.04 b (DEAN et al., 1992).

\section{Resultados}

\section{Sequenciamento do gene MSP5}

O sequenciamento resultou em um fragmento de $630 \mathrm{pb}$. A sequência completa do gene MSP5 da amostra PR-1 de $A$. marginale foi adicionada no GenBank, e o código de acesso é AY714547. O alinhamento e análise da sequência nos programas BLASTn e BLASTx mostrou que o gene MSP5 PR-1 apresenta 98\% de identidade com os isolados Flórida (M93392) e Saint Maries (CP 00030); 97\% com os isolados de Havana (AY527217) e Brasil-Pernambuco (AY245428) e 91\% com A. centrale (AY054384).

\section{Construção do plasmídio recombinante pRSET/msp5}

A clonagem do gene $m s p 5$ de A. marginale-PR1 no vetor $\mathrm{pRSET}_{\mathrm{B}}$ foi confirmada por meio da PCR do plasmídio recombinante e pela clivagem com enzima de restrição BamHI. Na Figura 1, observa-se o produto de amplificação, fragmento de aproximadamente $0.6 \mathrm{~kb}$, do $\mathrm{pRSET}_{\mathrm{B}} / \mathrm{MSP} 5$ utilizando os primers do gene $m s p 5$ e a clivagem do $\mathrm{pRSET}_{\mathrm{B}} / \mathrm{MSP} 5$ com a enzima de restrição BamHI. O produto final da clivagem foi um fragmento de aproximadamente $3,5 \mathrm{~kb}$, que contém o gene $m s p 5(0,6 \mathrm{~kb})$ e o vetor de $2,9 \mathrm{~kb}$.

\section{Expressão e caracterização antigênica da proteina rMSP5-PR1}

A expressão da proteína rMSP5-PR1 foi realizada em E. coli BL21 Star (DE3) One Shot ${ }^{\mathrm{TM}}$ (Invitrogen ${ }^{\circ}$ ), após indução com IPTG por 4 horas, e a proteína recombinante mostrou-se insolúvel. A rMSP5-PR1 purificada sob condiçóes híbridas apresentou uma banda induzida de $31 \mathrm{kDa}$ em SDS-PAGE 12\% (Figura 2a).

A BL21/pRSET/msp5 e a proteína rMSP5-PR1 purificada apresentaram reatividade com o anticorpo monoclonal ANAF16C1-HRPO produzido contra a MSP5 Flórida no Western blotting (Figura 2b). Esse monoclonal anti-MSP5 ANAF16C1 também reagiu com a proteína MSP5 de corpúsculo inicial do isolado de $A$. marginale PR1, identificando uma banda de $19 \mathrm{kDa}$, correspondente à massa molecular da proteína nativa (Figura 2b).

Os soros de bovinos, natural e experimentalmente infectados $\operatorname{com} A$. marginale, e o soro de coelho imunizado com rMSP5-PR1 reconheceram os epítopos da rMSP5-PR1 pela técnica Western blotting (Figura 3).

\section{Avaliação do cELISA-PRI}

Na padronização do teste, 135 soros negativos e 148 positivos foram testados pelas técnicas de IFI e cELISA-PR1, tendo o cELISA-USA. Os 135 soros negativos apresentaram 100\% de resultados concordantes. Entre os 148 soros positivos, foram detectados um resultado divergente no cELISA-PR1 e 3 na IFI (Tabela 1 e Figura 4). Os cálculos da concordância percentual, especificidade, sensibilidade, valores preditivo positivo e negativo e valores de kappa podem ser visualizados na Tabela 2 .

A Tabela 3 e a Figura 5 mostram os resultados de 245 soros de bovinos de região endêmica, analisados pelos cELISA-PR1 e IFI frente ao cELISA-USA. Foram identificados resultados divergentes em dois soros negativos e dois positivos no cELISA-PR1, sete soros negativos e 17 positivos na IFI. A Tabela 4 mostra os porcentuais de concordância, sensibilidade, especificidade, valores preditivo positivo e negativo e valores de kappa desses mesmos soros. 


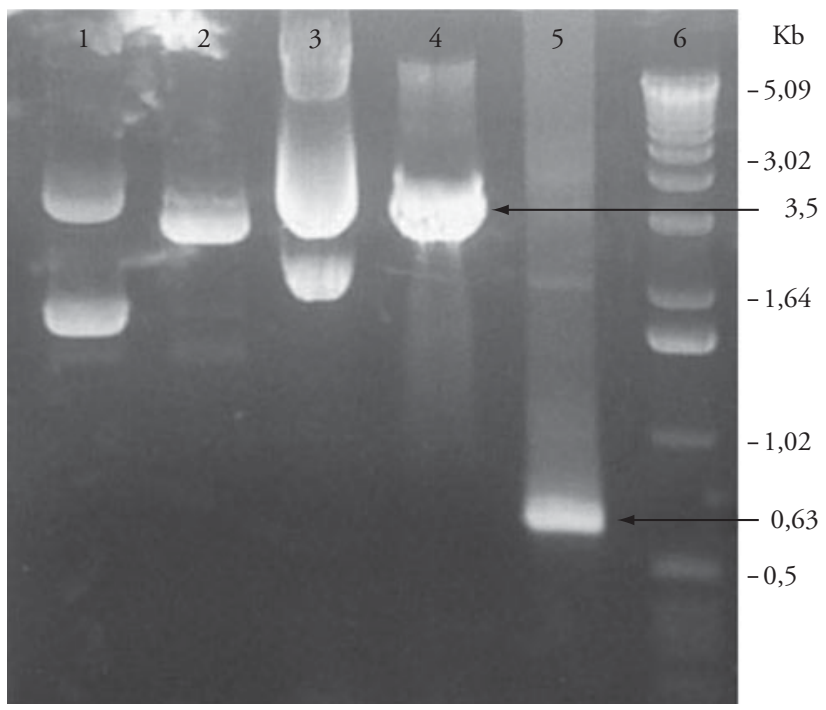

Figura 1. Plasmídio recombinante pRSET/MSP5 de Anaplasma marginale, visualizado em gel de agarose $1 \%$ após clivagem com a enzima de restrição BamHI. 1: pRSET $_{\mathrm{B}}$ (vetor) sem clivar; 2: vetor clivado com BamHI; 3: $\mathrm{pRSET}_{\mathrm{B}} / m s p 5$ não clivado; 4: $\mathrm{pRSET}_{\mathrm{B}} / m s p 5$ clivado com BamHI; 5: PCR de pRSET $_{\mathrm{B}}$ /msp; 6: Padrão de massa molecular $1 \mathrm{~kb}$ (GIBCO BRL ${ }^{\circ}$ ). Seta maior: fragmento de DNA contendo o gene MSP5 (0,6 kb) + o vetor (2,9 kb). Seta menor: fragmento de DNA que corresponde ao gene $m s p 5$.
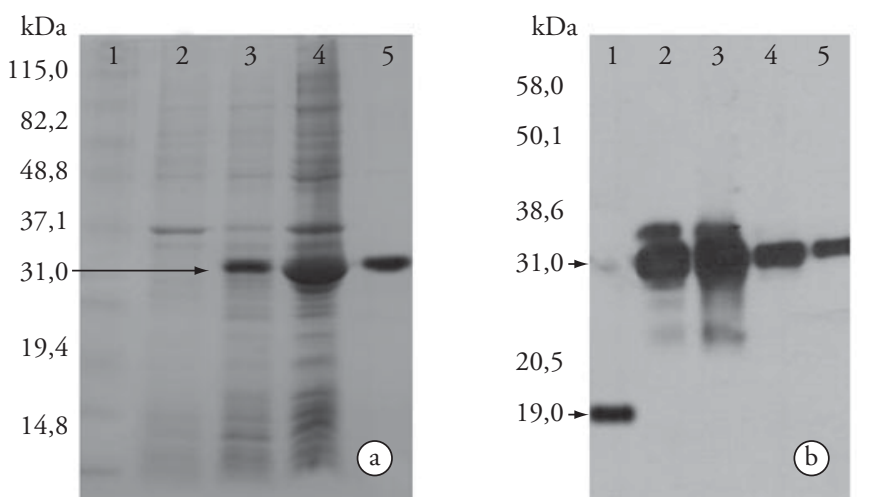

Figura 2. Proteína rMSP5-PR1 de Anaplasma marginale purificada sob condições híbridas em coluna de Resina de Níquel. a) SDS-PAGE $12 \%$ corado com Comassie blue. Coluna 1: padrão de massa molecular (Proteína Bench Mark - INVITROGEN ${ }^{\oplus}$ ); coluna 2: lisado da E. coli BL21 Star DE3; coluna 3: E. coli BL21/ pRSET $_{\text {в }}$ msp5 sem indução de IPTG; coluna 4: E. coli BL21/ pRSET $_{\text {B }}$ msp5 com indução de IPTG; coluna 5: rMSP5-PR1 purificada. b) Western blotting, a rMSP5-PR1 utilizando anticorpo monoclonal ANAF16C1-HRPO: coluna 1: corpúsculo inicial da cepa Flórida (19 kDA); coluna 2: E. coli BL21/pRSET m $_{\mathrm{B}} 5$ sem indução de IPTG; coluna 3: E. coli BL21/pRSET B $_{\mathrm{B}}$ 5 5 com indução de IPTG; coluna 4: lisado de $E$. coli BL21/ pRSET-msp5; coluna 5: rMSP5-PR1 purificada $(31 \mathrm{kDa})$. Seta maior - Figura a) indica tamanho molecular da MSP5 (19 kDa) + histidina (12 kDa). Setas menores da Figura b) (alto): reatividade da MSP5 fusionada na histidina em diferentes condiçóes, (baixo): reatividade da MSP5 nativa de corpúsculos iniciais de $A$. marginale.

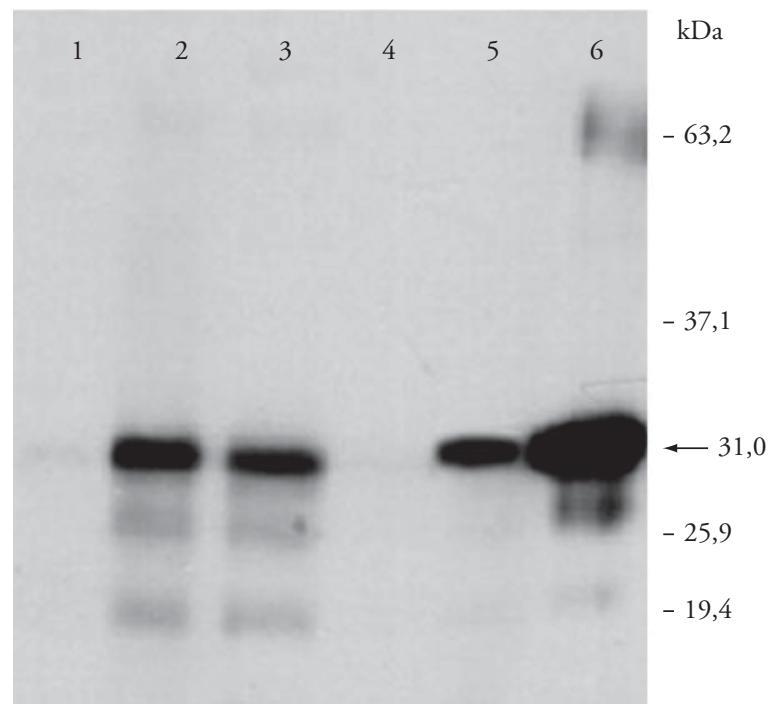

Figura 3. Western blotting da rMSP5-PR1 com anticorpos policlonais de bovinos natural e experimentalmente infectados e de coelho inoculado com rMSP5-PR1. Colunas 1 e 4: soro de bovino negativo para Anaplasma marginale; coluna 2: soro de bovino inoculado experimentalmente com o isolado de $A$. marginale PR1; colunas 3 e 5: soro de bovino positivo para $A$. marginale naturalmente infectado; coluna 6: soro de coelho experimentalmente inoculado com rMSP5r-PR1 de A. marginale. Seta: indica reatividade da MSP5 (19 kDa) + histidina $(12 \mathrm{kDa})$ com soros policlonais de bovinos e coelhos.

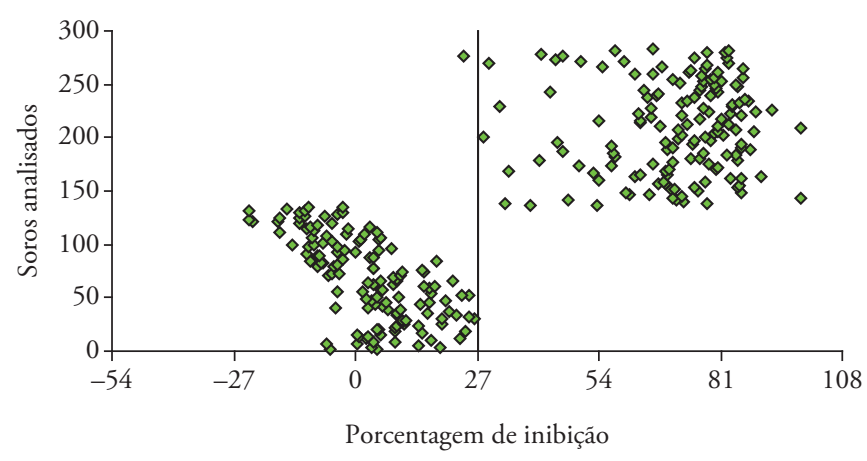

Figura 4. Distribuição da porcentagem de inibição da rMSP5-cELISA-PR1 de 135 soros bovinos sabidamente negativos, oriundos de Santa Vitória do Palmar, RS, e 148 soros de bovinos sabidamente positivos, naturalmente infectados por Anaplasma marginale.

Tabela 1. Comparação entre as técnicas de cELISA-PR1 e IFI com o cELISA-USA, utilizando-se soros de bovinos positivos e negativos para anticorpos anti-Anaplasma marginale. Londrina, Paraná, 2007.

\begin{tabular}{llrcc}
\hline \multirow{2}{*}{ Técnicas } & & \multicolumn{2}{c}{ cELISA-USA } & \multirow{2}{*}{ Total } \\
\cline { 3 - 4 } & & Positivo & Negativo & \\
\hline \multirow{2}{*}{ cELISA-PR1 } & Positivo & 147 & 0 & 147 \\
& Negativo & 1 & 135 & 136 \\
\multirow{2}{*}{ IFI } & Positivo & 145 & 0 & 145 \\
Total & Negativo & 3 & 135 & 138 \\
\hline
\end{tabular}


Tabela 2. Desempenho das técnicas de cELISA-PR1 e IFI na comparação com o cELISA-USA, utilizando-se soros de bovinos positivos e negativos para anticorpos anti- $A$. marginale. Londrina, Paraná, 2007.

\begin{tabular}{lcc}
\hline \multirow{2}{*}{\multicolumn{1}{c}{ cELISA }} & \multicolumn{2}{c}{ Técnicas } \\
\cline { 2 - 3 } & cELISA-PR1 & IFI \\
\hline Concordância & $99,6 \%$ & $98,93 \%$ \\
Sensibilidade & $99,3 \%$ & $100,0 \%$ \\
Especificidade & $100,0 \%$ & $98,0 \%$ \\
Valor preditivo positivo & $100,0 \%$ & $100,0 \%$ \\
Valor preditivo negativo & $99,3 \%$ & $97,8 \%$ \\
kappa & $0,993^{\mathrm{QP}}$ & $0,978^{\mathrm{QP}}$ \\
\hline
\end{tabular}

kappa $(\mathrm{k})$ - coeficiente kappa $(<0,0$ a 1,0$)$; $\mathrm{QP}=$ quase perfeito: $0,81-1,00$.

\section{Discussáo}

Os altos índices de identidade do gene $m s p 5$ da amostra PR1 de A. marginale com a amostra Flórida e Saint Maries (98\%), Havana e Brasil-PE (97\%) e A. centrale (91\%) confirmam a conservação da MSP5 nos diferentes isolados de diferentes regióes (TEBELE et al., 1991; VISSER et al., 1992; NDUNG'U et al., 1995).

Neste trabalho, a rMSP5, originalmente com $19 \mathrm{kDa}$, foi identificada com massa molecular de $31 \mathrm{kDa}$ devido à característica do vetor de expressão $\mathrm{pRSET}_{\mathrm{B}}$, que codifica uma proteína recombinante fusionada a $6 x$ Histidina e ao XPress. Essas proteínas aumentam a massa molecular da proteína fusionada em $12 \mathrm{kDa}$, o que explica os $31 \mathrm{kDa}$ da rMSP5-PR1.

Além de sua antigenicidade, uma característica importante em uma proteína recombinante, para ser escolhida como antígeno em um teste imunoenzimático, é a conservação dos seus epítopos em cepas de diferentes regióes geográficas. A rMSP5-PR1 mostrou-se conservada por meio da reatividade com o anticorpo monoclonal ANAF16C1 pelo Western blotting. Esse monoclonal anti-MSP5 ANAF16C1 reage com a rMSP5 fusionada na proteína de ligaçáo à maltose (rMSP5-MBP), utilizada no teste de cELISA (KNOWLES et al., 1996), e também reagiu com a proteína MSP5 nativa de corpúsculo inicial do isolado de $A$. marginale PR1 (19 kDa) (Figura 2b), confirmando a conservação de epítopos da rMSP5-PR1 purificada sob condiçóes híbridas.

A conservação dos epítopos da rMSP5-PR1 está de acordo com o resultado do sequenciamento do gene $m s p 5$ do isolado PR1, o qual demonstra a similaridade entre outros isolados. Essa similaridade obtida no sequenciamento também corrobora os resultados de Visser et al. (1992), que demonstram a presença de um único gene conservado responsável pela MSP5, ao contrário das proteínas MSP1b, MSP2 e MSP3, que são codificadas por famílias multigenes (ALLEMAN et al., 1997; BARBET et al., 2001) e podem sofrer recombinação intragênica.

A rMSP5-PR1 também reagiu com soros homólogos e heterólogos de bovinos, natural e experimentalmente infectados com A. marginale (Figura 3), e com o soro de coelho imunizado com rMSP5-PR1, o que reforça os resultados observados em trabalhos anteriores (KANO et al., 2002; OLIVEIRA et al., 2003), os quais demonstraram a conservação da MSP5 em isolados brasileiros pelo Western blotting.
Tabela 3. Comparação entre as técnicas de cELISA-PR1 e IFI com o cELISA-USA, utilizando-se soros de bovinos de áreas endêmicas para Anaplasma marginale. Londrina, Paraná, 2007.

\begin{tabular}{llccc}
\hline \multirow{2}{*}{ Técnicas } & & \multicolumn{2}{c}{ cELISA-USA } & \multirow{2}{*}{ Total } \\
\cline { 3 - 4 } & & Positivo & Negativo & \\
\hline \multirow{2}{*}{ cELISA-PR1 } & Positivo & 188 & 2 & 190 \\
& Negativo & 2 & 53 & 55 \\
\multirow{2}{*}{ IFI } & Positivo & 183 & 17 & 200 \\
\multirow{2}{*}{ Total } & Negativo & 7 & 38 & 45 \\
\hline
\end{tabular}

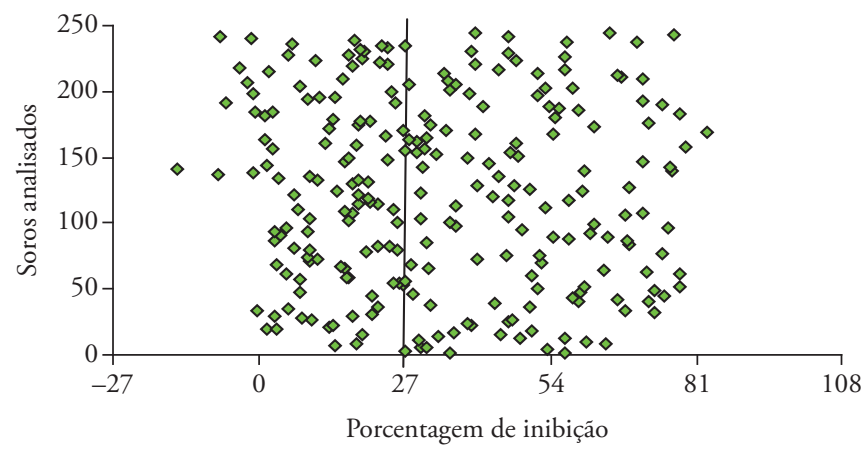

Figura 5. Distribuição da porcentagem de inibição da rMSP5-cELISA-PR1 de 245 soros bovinos de áreas endêmicas para Anaplasma marginale dos Estados do Paraná e Rio Grande do Sul.

A variação na massa molecular da proteína nativa de $19 \mathrm{kDa}$ para $31 \mathrm{kDa}$ na rMSP5-PR1 náo influenciou a reatividade da proteína no cELISA-PR1, da mesma forma que a MBP não interferiu no teste de cELISA-USA (KNOWLES et al., 1996) e também não influenciou no ELISA indireto com a MSP5 fusionada na GST (BARROS et al., 2005). Desde a descoberta e caracterização das MSPs de $A$. marginale, diversos autores têm demonstrado que a MSP5 é uma proteína altamente conservada entre diversos isolados e que estimula uma resposta humoral vigorosa que pode ser detectada por testes sorológicos durante longos períodos. Isso tem estimulado diversos autores a utilizarem a rMSP5 como antígeno em testes de cELISA (KNOWLES et al., 1996; TORIONI DE ECHAIDE et al., 1998) e ELISA indireto (REYNA-BELLO et al., 1998; BARROS et al. 2005).

No presente trabalho, utilizou-se a rMSP5-PR1, clonada a partir de uma amostra de $A$. marginale isolada de 1 bezerro com anaplasmose clínica, na região de Londrina, PR, e 1 cELISA com o anticorpo monoclonal ANAF16C1, com o objetivo de avaliar o desempenho dessa proteína recombinante local, comparativamente ao teste original de Knowles et al. (1996) validado por Torione de Echaide et al. (1998). Portanto, os resultados desse trabalho só podem ser comparados aos desses dois autores, uma vez que outros como Reyna-Bello et al. (1998) e Barros et al. (2005), avaliaram a rMSP5 em sistemas de ELISA indireto. Contudo, deve-se ressaltar que esses autores encontraram resultados muito próximos daqueles encontrados para os cELISA, o que demonstra a opção de uso dessa proteína recombinante nos sistemas de ELISA indireto, em substituição ao antígeno solúvel 
de difícil purificação e padronização, obtido a partir de eritrócitos infectados com corpúsculos iniciais de $A$. marginale.

Knowles et al. (1996) mostraram que o cELISA-USA foi capaz de detectar anticorpos anti- $A$. marginale, 19 dias após a exposição de bovinos a carrapatos infectados e dois dias antes do aparecimento de $A$. marginale no sangue desses animais. Esse teste apresentou especificidade de $100 \%$, quando 268 soros oriundos de bovinos sabidamente negativos foram testados.

Torioni de Echaide et al. (1998) validaram o cELISA-USA utilizando 235 soros de uma área endêmica para anaplasmose localizada no Oeste do estado do Oregon, EUA, tendo como uma nested PCR, que permite identificar animais são portadores de baixíssimos níveis de parasitemia, e encontraram sensibilidade de $96 \%$ e especificidade de $95 \%$, respectivamente.

$\mathrm{Na}$ avaliação das técnicas utilizadas neste trabalho, há de se considerar as duas situaçóes estudadas. Primeiro, o desempenho das técnicas de cELISA-PR1 e IFI com o cELISA-USA como frente a soros sabidamente positivos e negativos. Nessa situação, o cELISA-PR1 deixou de detectar apenas 1 entre os soros positivos, e a IFI não identificou três soros positivos (Tabela 1). Observando-se os valores de kappa, especificidade e sensibilidade (Tabela 2) alcançados pelo cELISA-PR1, o teste realizado nesse trabalho demonstrou alta concordância ao ser comparado com o cELISA-USA. Isso permite concluir que a rMSP5-PR1 utilizada na padronização do teste apresentou características similares àquelas do isolado Flórida. Além do mais, o resultado do sequenciamento do gene que codifica a MSP5-PR1 mostrou 98\% de identidade com a sequência gênica da cepa Flórida do $A$. marginale utilizada no cELISA-USA. Da mesma forma, nessa situação, a IFI apresentou um desempenho satisfatório na identificação dos soros verdadeiramente positivos ou negativos, com concordância, sensibilidade e especificidade semelhantes ao cELISA-PR1 (Tabela 2). Por outro lado, quando as duas técnicas foram confrontadas frente a soros não conhecidos, de animais de área endêmica, houve uma grande discrepância entre as duas técnicas na identificação tanto de soros positivos como de negativos, com nítida vantagem para o cELISA-PR1 (Tabelas 3 e 4).

Há muito tempo que a IFI é considerada uma técnica padrão para o diagnóstico sorológico de diversas doenças parasitárias, dentre elas a anaplasmose. No passado, essa técnica foi utilizada em diversos levantamentos sorológicos e na avaliação de programas de vacinação de $A$. marginale (MADRUGA et al., 1986; VIDOTTO et al., 1997; ALFARO et al., 1998; ARAÚJO et al., 1998; MADRUGA et al., 2000; DIAZ et al. 2003; MELÉNDEZ et al., 2003). Problemas, como diferentes níveis de fluorescência, fluorescência inespecífica, baixa qualidade da amostra, fadiga do operador e resultados influenciados pela subjetividade do operador, aliados aos avanços no desenvolvimento dos testes imunoenzimáticos, podem ser citados como fatores que ultimamente têm contribuído para o uso limitado dessa técnica (GOFF et al., 1985; BÖSE et al., 1995; YOSHIHARA et al., 2003; BARROS et al., 2005).

Os resultados obtidos mostram que o teste de cELISA-PR1 padronizado com rMSP5 do isolado PR1 de $A$. marginale apresentou performance equivalente ao cELISA-USA, que utiliza a rMSP5-MBP do isolado de $A$. marginale Flórida para diagnosticar anaplasmose, podendo também ser utilizado em estudos epidemiológicos, programas de controle e movimentação internacional de animais.
Tabela 4. Desempenho das técnicas de cELISA-PR1 e IFI na comparação com o cELISA-USA, utilizando-se soros de bovinos de áreas endêmicas para Anaplasma marginale. Londrina, Paraná, 2007.

\begin{tabular}{lcc}
\hline \multirow{2}{*}{\multicolumn{1}{c}{ cELISA-USA }} & \multicolumn{2}{c}{ Técnicas } \\
\cline { 2 - 3 } & cELISA-PR1 & IFI \\
\hline Concordância & $98,37 \%$ & $93,7 \%$ \\
Sensibilidade & $98,9 \%$ & $96,3 \%$ \\
Especificidade & $96,4 \%$ & $69,1 \%$ \\
Valor preditivo positivo & $98,9 \%$ & $91,5 \%$ \\
Valor preditivo negativo & $96,4 \%$ & $84,5 \%$ \\
kappa & $0,956^{\mathrm{QP}}$ & $0,699^{\mathrm{S}}$ \\
\hline
\end{tabular}

kappa $(\kappa)$ - coeficiente kappa $(<0,0$ a 1,0$) ; S=$ substancial: $0,61-0,80$; $\mathrm{QP}=$ quase perfeito: $0,81-1,00$.

\section{Referências}

ANDRADE, G. M. et al. Soroprevalência de Anaplasma marginale em bovinos leiteiros e estudo sobre a dinâmica da infecçáo natural em bezerros holandeses no Sul do Brasil. Semina: Ciências Agrárias, v. 22, n. 2, p. 155-159, 2001.

ALFARO, C. et al. Epidemiología de la anaplasmosis bovina en el estado Monagas: asociación con factores extrínsecos e intrínsecos del hospedador. Veterinary Tropical, v. 23, n. 1, p. 65-79, 1998.

ALLEMAN, A. R. et al. Anaplasma marginale Major Surface Protein 3 is encoded by a polymorphic, multigene family. Infection and Immunity, $v$. 65 , n. 1, p. 156-163, 1997.

ALTSCHUL, S. F. et al. Basic local alignment search tool. Journal of Molecular Biology, v. 215, n. 3 p. 403-410, 1990. Disponível em: <http:// www.ncbi.nlm.nih.gov>. Acesso em: 16 de Junho de 2006.

ALTSCHUL, S. F. et al. Gapped BLAST and PSI-BLAST: a new generation of protein database search programs. Disponível em: <http://www.ncbi.nlm. nih.gov>. Acesso em: 16 de Junho de 2006.

ARAÚJO, F. R. et al. Comparison between enzyme-linked immunosorbent assay, indirect fluorescent antibody and rapid conglutination tests in detecting antibodies against Babesia bovis. Veterinary Parasitology, v. 74, n. 2-4, p. 101-108, 1998.

ARAÚJO, F. R. et al. Levantamento sorológico para Anaplasma marginale em duas microrregióes do estado da Bahia. Revista Brasileira de Parasitologia Veterinaria, v. 4, n. 2, p. 188, 1995.

BARBET, A. F. et al. Antigenic variation of Anaplasma marginale: Major Surface Protein 2 diversity during cyclic transmission between ticks and cattle. Infection and Immunity, v. 69, n. 5, p. 3057-3066, 2001.

BARROS, S. L. et al. Serological survey of Babesia bovis, Babesia bigemina and Anaplasma marginale antibodies in cattle from the semi-arid region of state of Bahia, Brazil, by enzyme-linked immunosorbent assays. Memórias do Instituto Oswaldo Cruz, v. 100, n. 6, p. 513-517, 2005.

BÖSE, R. et al. Current state and future trends in the diagnosis of babesiosis. Veterinary Parasitology, v. 57, n. 1-3, p. 61-74, 1995.

BRADFORD, M. A rapid and sensitive method for the quantitation of microgram quantities of protein utilizing the principle of protein-dye biding. Analytical Biochemistry, v. 72, n. 1-2, p. 248-254, 1976.

DEAN, A. G.; DEAN, I. A.; BURTON, A. H. EPI INFO version 6.04: a world processing data base and statistic program for epidemiology on microcomputers. Atlanta: Center for Disease Control, 1992. 302 p. Disponível em: <http//:www. cdc.gov>. Acesso em: 05 de Janeiro de 2006. 
DIAZ, D. et al. Prevalencia de Anaplasma marginale em bovinos del sector le Piñata, Municipio La Cañada de Urdaneta, Estado Zulia, Venezuela. Revista Científica, v. 13, n. 3, p. 193-198, 2003.

DUMLER, J. S. et al. Reorganization of genera in the families Rickettsiaceae and Anaplasmataceae in the order Rickettsiales: unification of some species of Ehlrlichia with Anaplasma, Cowdria with Ehrlichia and Ehrlichia with Neorickettsia, descriptions of six new species combinations and designation of Ehrlichia equi and 'HGE agent' as subjective synonyms of Ehrlichia phagocytophila. International Journal of Systmatic and Evolucinary Microbiology, v. 51, n. 4, p. 2145-2165, 2001.

FraGAdA, M.; CORDOVES, C. O.; PUENTES, T. Circulación de anticuerpos de hemoparásitos en ganado (Bos taurus) de alto valor genético en la República de Cuba. Revista Cubana de Ciencias Veterinarias, v. 22, n. 3, p. 249-255, 1991.

GOFF, W. L.; JOHNSON, W. C.; KUTTLER, K. L. Development of an indirect fluorescent antibody test, using microfluorometry as a diagnostic test for bovine anaplasmosis. American Journal of Veterinary Research, v. 46, n. 5, p. 1080-1084, 1985.

JONGEJAN, F. et al. Epidemiology of bovine babesiosis and anaplasmosis in Zambia. Tropical Animal Health and Production, v. 20, n. 4, p. 234242, 1988 .

KANO, S. F. et al. Antigenic characterization of Anaplasma marginale isolates from different regions of Brazil. Veterinary Microbiology, v. 87, n. 2, p. $131-138,2002$

KESSLER, R. H. Consideraçôes sobre a transmissão de Anaplasma marginale. Pesquisa Veterinária Brasileira, v. 21, n. 4, p. 139-179, 2001.

KNOWLES, D. P. et al. Antibody against Anaplasma marginale MSP-5 epitope common to tick and erythrocyte stages identifies persistently infected cattle. Journal Clinical Microbiology, v. 34, n. 9, p. 2225-2230, 1996.

KREIER, J. P.; RISTIC, M. The biology of hemotrophic bacteria. Annual Review Microbiollogy, v. 35, n. 3, p. 325-38, 1981.

LAEMMLI, U. K. Cleavage of structural proteins during the assembly of head of bacteriophage T4. Nature, v. 227, n. 5259, p. 680-685, 1970.

MADRUGA, C. R. et al. Evaluation of an enzyme linked immunosorbent assay to detect antibodies against Anaplasma marginale. Pesquisa Veterinária Brasasileira, v. 20, n. 3, p. 109-112, 2000.

MADRUGA, C. R. et al. Produçáo de antígenos e análise preliminar do teste de Imunofluorescência Indireta para diagnóstico de anticorpos contra Anaplasma marginale. Campo Grande: EMBRAPA-CNPGC, 1986. 4 p. Circular Técnico n. 31.

MADRUGA, C. R. et al. Evaluation of an enzyme linked immunosorbent assay to detect antibodies against Anaplasma marginale. Pesquisa Veterinária Brasileira, v. 20, n. 3, p. 109-112, 2000.

MELÉNDEZ, R. D. et al. Humoral immune response and hematologic evaluation of pregnant Jersey cows after vaccination with Anaplasma centrale. Veterinary Microbiology, v. 94, n. 4, p. 335-339, 2003.

NAKAMURA, Y. et al. Enzyme-linked immunosorbent assay using solubilised antigen for detection of antibodies to Anaplasma marginale. Tropical Animal Health and Production, v. 20, n. 4, p. 259-266, 1988.

NDUNG'U, L. W. et al. Detection of Anaplasma ovis infection in goats by major surface protein 5 competitive inhibition enzyme-linked immunosorbent assay. Journal Clinical Microbiology, v. 33, n. 3, p. 675-679, 1995.

NIELSEN, K. et al. Development and validation of an indirect enzyme immunoassay for detection of antibody to Anaplasma marginale in bovine sera. Veterinary Parasitology, v. 67, n. 3-4, p. 133-142, 1996.
OBERLE, S. M.; PALMER, G. H.; BARBET, A. F. Expression and immune recognition of the conserved MSP-4 outer membrane protein of Anaplasma marginale. Infection and Immunity, v. 61, n. 12, p. 5245-5251, 1993.

OLIVEIRA, A. A. et al. Doenças de bezerros. II. Epidemiologia da anaplasmose no estado de Sergipe. Arquivo Brasileiro de Medicina Veterinária e Zootecnia, v. 44, n. 5, p. 377-386, 1992.

OLIVEIRA, J. B. et al. Antigenic characterization of Brazilian isolates of Anaplasma marginale. Memórias do Instituto Oswaldo Cruz, v. 98, n. 3, p. 395-400, 2003.

PALMER, G. H.; McGUIRE, T. C. Immune serum against Anaplasma marginale initial bodies neutralizes infectivity for cattle. Journal of Immunology, v. 133, n. 2, p. 1010-1015, 1984.

PEREZ, E. et al. Epidemiology of bovine anaplasmosis and babesiosis in Costa Rica. Preventive Veterinary Medicine, v. 20, n. 1-2, p. 23-31, 1994.

REYNA-BELLO, A. et al. Evaluation of an enzyme-linked immunosorbent assay using recombinant major surface protein 5 for serological diagnosis of bovine anaplasmosis in Venezuela. Clinical and Diagnostic Laboratory Immunology, v. 5, n. 2, p. 259-262, 1998.

RODGERS, S. J.; WELSH, R. D.; STEBBINS, M. E. Seroprevalence of bovine anaplasmosis in Oklahoma from 1977 to 1991. Journal of Veterinary Diagnostic Investigation, v. 6, n. 2, p. 200-206, 1994.

ROSE, J. E. et al. Serum levels of conglutinin, complement, and immunoconglutinin in cattle infected with Anaplasma marginale. American Journal of Veterinary Research, v. 39, n. 5, p. 791-793, 1978.

SAMBROOK, J.; FRITSCH, E. F.; MANIATIS, T. Molecular cloning: a laboratory manual. 2 ed. New York: Cold Spring, 1989. 345 p.

TEBELE, N.; PALMER, G. H. Crossprotective immunity between the Florida and a Zimbabwe stock of Anaplasma marginale. Tropical Animal Health and Production, v. 23, n. 4, p. 197-202, 1991.

TORIONI DE ECHAIDE, S. et al. Detection of cattle naturally infected with Anaplasma marginale in a region of endemicity by nested PCR and competitive enzyme linked immunosorbent assay using recombinant major surface protein-5. Journal Clinical Microbiology, v. 36, n. 3, p. 777-782, 1998.

TOWBIN, H.; GORDON, H. Immunoblotting and dot immunobinding: current status and Outlook. Journal of Immunological Methods, v. 72, n. 2, p. 313-340, 1984.

VIDOTTO, O. et al. Frequência de anticorpos contra Babesia bigemina, $B$. bovis e Anaplasma marginale em rebanhos de bovinos leiteiros da região de Londrina, Paraná. Arquivo Brasileiro de Medicina Veterinária e Zootecnia, v. 49, n. 5, p. 655-659, 1997.

VIDOTTO, M. C. et al. Seroprevalence of Anaplasma marginale in cattle in Parana State, Brazil, by MSP5 competitive inhibition ELISA. Annals of New York Academy of Sciences, v. 849, p. 424-426, 1998.

VISSER, F. S. et al. The Anaplasma marginale MSP-5 gene encodes a 19 kilodalton protein conserved in all recognized Anaplasma species. Infection and Immunity, v. 60, n. 12, p. 5139-5144, 1992.

YOSHIHARA, E. et al. Studies of natural infection with Anaplasma marginale in nelore cattle in the Umuarama municipality, Parana State, Brazil. Revista Brasileira de Parasitologia Veterinária, v. 12, n. 1, p. 21-26. 2003. 